\title{
A construção do ethos refletido nas entrevistas das presidentas Sul-americanas
}

\author{
Paula Camila Mesti \\ Universidade Federal de São Carlos (UFSCar), São Carlos, São Paulo, Brasil \\ paulamesti@hotmail.com \\ http://orcid.org/0000-0002-9778-5347
}

DOI: $\underline{\text { http://dx.doi.org/10.21165/el.v47i3.1970 }}$

\begin{abstract}
Resumo
Com os deslocamentos epistemológicos que a multiplicação dos gêneros discursivos (principalmente os digitais) possibilitaram, a noção de ethos passou a apresentar muitas dificuldades que resultaram em uma diversidade de trabalhos sobre este tema. Com base em um corpus de entrevistas das presidentas Sul-americanas - Michelle Bachelet, Cristina Kirchner e Dilma Rousseff - e considerando o conceito de ethos discursivo, este artigo tem como objetivo apresentar e discutir os recentes deslocamentos epistemológicos deste conceito, demonstrando gestos interpretativos que evidenciam que o ethos, para além de ser construído pelo destinatário do discurso, pode ser construído nos enunciados das questões feitas pelos jornalistas, nos enunciados das respostas dadas por essas presidentas e nos comentários que os internautas postam no canal YouTube.

Palavras-chave: ethos discursivo; deslocamento epistemológico; ethos refletido; ethos fixado.

\section{The construction of the reflected ethos in the interviews of the South American presidents}

\begin{abstract}
With the epistemological displacements that the multiplication of the discursive (mainly digital) genres allowed, the notion of ethos began to present many difficulties that resulted in a diversity of works on this subject. Based on a corpus of interviews of the South American presidents Michelle Bachelet, Cristina Kirchner and Dilma Rousseff and even considering the concept of discursive ethos, this article aims to present and discuss the recent epistemological displacements of this concept, demonstrating interpretative gestures that show that the ethos, in addition to being built by the receiver of the speech, can be constructed in the statements of the questions made by the journalists, in the statements of the answers given by these female presidents and in the comments that the internet users have posted about the videos available on YouTube.
\end{abstract}

Keywords: discursive ethos; epistemological shift; reflected ethos; set ethos.

\section{Introdução}

Durante os séculos ocorreram muitas transformações na História, sobretudo na História sobre a mulher. Segundo Araújo (2011), nos séculos XVII e XVIII, o papel da mulher esteve atrelado ao universo familiar e doméstico. Para a sociedade, a mulher tinha a missão de ter filhos, cuidar do marido e da família. Apesar das mudanças nas práticas sociais relacionadas às mulheres no século XX no Brasil, havia diferenças entre os papéis masculinos e femininos. De acordo com Bassanezi (2001), permanecia forte a distinção da moral sexual e, ainda que tenha se tornado mais comum a mulher trabalhar, tal atitude 
era cercada de preconceito e vista como auxílio ao trabalho do homem. No século XXI, a mulher conquista o direito de construir-se a si própria, saindo da inércia e não se submetendo aos discursos conservadores. A mulher do terceiro milênio, explica Confortin (2003), privilegia a qualidade de vida e comemora suas conquistas: moradia, lazer, saúde e liberdade.

Na política, a entrada da mulher, a conquista do seu espaço foi tardia. No Brasil, o direito pleno do voto para todas as mulheres foi instituído pela Constituição de 1946. Somente a partir dos anos 60 é que elas começaram a marcar presença na arena política e, no ano de 2010, o Brasil teve a primeira mulher eleita por voto direto para ocupar o cargo de Presidente da República.

Além das mudanças na História das mulheres, pode-se afirmar que a mídia também realizou transformações, sobretudo nas práticas discursivas, e com elas, no próprio discurso político. A comunicação política que há algumas décadas tinha como alicerce, quase exclusivamente, a palavra, fosse ela falada ou impressa, agora tem como base o uso da imagem e de outras semioses.

Observando-se a predominância da imagem, a velocidade da transmissão de informações, a supervalorização da mídia, a metamorfose ocorrida na maneira de se fazer política, a atuação da mulher em ambientes predominantemente masculinos, a impossibilidade de se separar o verbo do corpo que enuncia são práticas corriqueiras no atual mundo globalizado. Os analistas do discurso passaram a analisar o texto e o discurso, identificando os procedimentos de textualização, de discursivização, os efeitos de sentido, de memória e historicidade.

É justamente essa pressão das mídias audiovisuais e da publicidade sobre as condições do exercício da palavra publicamente proferida, que, segundo Maingueneau (2005), fundamentam o interesse crescente pelo ethos, que pode ser entendido como a imagem de si construída no discurso.

Baseando-se nas transformações ocorridas no discurso político contemporâneo, na presença da mulher na política e no dispositivo teórico da Análise do Discurso, o presente artigo tematiza o modo de construção das imagens de si que os sujeitos políticos femininos Michelle Bachelet (Partido Socialista-Chile), Cristina Fernández de Kirchner (Partido Justicialista - Argentina) e Dilma Rousseff (Partido dos Trabalhadores - Brasil) apresentam em seus discursos durante entrevistas veiculadas na mídia televisiva quando eram presidentas da República em seus primeiros mandatos.

Desta sorte, são as seguintes inquietações que norteiam e estruturam nosso trabalho: I) Quais tipos de ethé ${ }^{I}$ são construídos nas entrevistas desses sujeitos políticos? II) Como os enunciados produzidos pelos jornalistas/entrevistadores podem produzir diferentes efeitos de sentido para a imagem de si das presidentas? III) Os comentários postados nos vídeos das entrevistas também contribuem para a construção dos ethé das presidentas?

\footnotetext{
${ }^{1}$ Do grego, ethé indica plural de ethos.
} 


\section{A noção de ethos e seus deslocamentos contemporâneos}

A noção de ethos discursivo como construção de uma imagem de si no discurso é pesquisada nos trabalhos de Maingueneau desde a década de 1980. A problemática que esse professor de Ciências da Linguagem desenvolve visa articular corpo e discurso, indo além da oposição oral versus escrito.

Para se alcançar esse pensamento e possibilitar sua integração aos pressupostos da Análise do Discurso, Maingueneau (1997) fez um duplo deslocamento na questão do ethos retórico. O primeiro refere-se ao fato de que o enunciador não possuiria intenções, pois ele não desempenha o papel de sua escolha em virtude dos efeitos que pretende produzir. Esses efeitos são atravessados pela Formação Discursiva, que determina uma posição no discurso. No segundo deslocamento, observa-se a ausência da oposição oral e escrita. Isso se deve ao fato de que mesmo os corpora escritos possuem uma oralidade, são dotados e sustentados por uma voz específica, possuem uma textualidade.

À luz dos estudos feitos pelo referido autor, pode-se compreender que a noção de ethos concorda com algumas ideias advindas da Retórica de Aristóteles, sobretudo nestes três aspectos: a) por se constituir por meio do discurso, o ethos não é uma "imagem" do locutor exterior à fala, mas uma noção discursiva; b) é um processo interativo de influência sobre o outro; c) é uma noção sócio-discursiva que não pode ser apreendida fora de uma situação de comunicação precisa.

Ao dissertar sobre suas concepções de ethos, Maingueneau (2008a, p. 64) assevera: "Minha perspectiva ultrapassa bastante o quadro da argumentação. Além de persuasão pelos argumentos, a noção de ethos permite refletir sobre o processo mais geral da adesão dos sujeitos a certo posicionamento". Ainda sob o prisma da teoria elaborada por Maingueneau (2013, p. 73), fala-se de "incorporação" para designar a maneira pela qual os coenunciadores se relacionam ao ethos de um discurso. Para que essa incorporação aconteça, o ethos pode ser construído no discurso de duas maneiras diferentes: ele pode ser dito ou mostrado. Conforme ensinado por Maingueneau (2008a), o ethos dito consiste em fragmentos de textos em que o enunciador evoca sua própria enunciação, enuncia sobre ele mesmo. Por outro lado, o ethos mostrado, considerado por Maingueneau (2008a, 2008b, 2010, 2013) como o verdadeiro ethos discursivo, é construído pelo coenunciador (destinatário) a partir de vestígios deixados na enunciação.

É possível afirmar que a noção de ethos apresenta muitas dificuldades devido à multiplicação de trabalhos sobre este tema, fato que revela a necessidade de contínuas reflexões teórico-metodológicas. Além de todas as diferenças já existentes na noção de ethos discursivo, observou-se que, nos últimos anos, vários autores iniciaram algumas ampliações deste conceito. Começou-se a explorar a possibilidade de o ethos ser construído não apenas no discurso "daquele que enuncia", mas também por seus parceiros de enunciação.

Para explicitar a importância da noção do ethos no gênero debate político, Sandré (2014) analisa o debate entre François Hollande e Nicolas Sarkozy, nas eleições presidenciais da França em 2012. Nesta empreitada, a autora analisa como o ethos é construído no discurso e no gênero com interação. Retomando a distinção feita entre 
"imagem afixada"2 e "imagem atribuída", Sandré (2014) afirma que o ethos em interação se constrói nesses dois planos. Esta estudiosa denomina a imagem que o locutor constrói de si mesmo (ethos discursivo) como imagem afixada no discurso (ethos dito) ou afixada pelo discurso (ethos mostrado). Essas imagens podem, ainda, ser apreendidas no comportamento dos sujeitos. A imagem afixada pelo locutor se encontra e confronta com a "imagem atribuída" por seus parceiros de interação, que também podem ser engendradas no discurso e pelo discurso do coenunciador.

Em seu artigo publicado na revista francesa Langage \& Societé n. 149, Amossy (2014) traz à lume a questão de que a noção de ethos não é explorada somente sob essa designação nos mais diversificados campos do saber, podendo também ser denominada de: "apresentação de si", "gestão de impressões", "imagem corporativa", "branding". Após apresentar as especificidades do ethos dentro das ciências da linguagem, Amossy (2014) ressalta a relevância da argumentação no discurso e o cruzamento da retórica com a análise do discurso ao analisar o livro autobiográfico de Ségolène Royal - Ma plus belle histoire, c'est vous - publicado em 2007, após sua derrota nas eleições presidenciais francesas. Nosso principal interesse nesse trabalho feito por Amossy (2014) são as análises que ela faz do livro mostrando um "retravail de l'ethos", que iremos traduzir como "reconstrução do ethos". Entende-se por reconstrução do ethos as estratégias discursivas e argumentativas usadas por Royal para transformar um ethos negativo em um ethos positivo, colocando-a como merecedora do apoio de seus eleitores após sua derrota nas urnas.

Em um de seus mais recentes trabalhos, Maingueneau (2014) afirma que a concepção usual de ethos discursivo é insuficiente e que, por isso, ele apresenta algumas modificações para esta noção e faz reflexões sobre a complexidade das estratégias que os destinatários devem mobilizar para atribuir um ethos ao enunciador. Ao considerar que o conteúdo que os analistas dão ao ethos depende do tipo e do gênero do discurso que é estudado, Maingueneau (2014) propõe atribuir três dimensões ao ethos a fim de tornar as análises mais eficazes: categórica, experiencial e ideológica.

Para o referido autor (Ibidem, p. 32, tradução nossa), a dimensão "categórica" abrange tanto os papéis discursivos, como os estatutos extradiscursivos. Entende-se como papéis discursivos aqueles relacionados à atividade de fala, por exemplo, animador, contador de histórias. Já os estatutos extradiscursivos seriam "pai de família", "funcionário", "solteiros". Em seu turno, a dimensão "experiencial" do ethos abrange as caracterizações sócio-psicológicas estereotipadas, por exemplo, "dinamismo do jovem executivo". E a dimensão "ideológica" refere-se a posicionamentos dentro de um campo, neste caso: "feminista", "de esquerda", "conservador".

Maingueneau (2014) explica que essas três dimensões interagem fortemente e que os analistas, em função do gênero e do tipo de discurso, têm a tendência de filtrar essas características. O autor cita o exemplo do gênero político eleitoral no qual o analista privilegia principalmente "[...] os predicados que pertencem ao posicionamento ideológico (de direita, pró-europeu, anarquista) e os predicados psicológicos pertinentes (competência, autoridade, honestidade, coragem)" (MAINGUENEAU, 2014, p. 33, tradução nossa).

\footnotetext{
${ }^{2} \mathrm{O}$ trabalho da professora Sandré (2014) está publicado em francês na revista Langage \& Société, portanto, o termo aqui foi traduzido por nós como "imagem afixada", mas aparece no original como "image affichée". Bem como o conceito de "image attribuée" também traduzido por nós como "imagem atribuída".
} 
Estudar o ethos, para Maingueneau (2014), é se apoiar a uma realidade simples, intuitiva, a um fenômeno que é coexistente a todo uso da língua: o destinatário constrói necessariamente uma representação do locutor por meio do seu dizer e da sua maneira de dizer. É pensando nas ações dos destinatários no momento da incorporação do ethos que Maingueneau (2014) aponta três possíveis estratégias ${ }^{3}$ usadas por eles para a gestão da relação entre o ethos dito e o ethos mostrado: a) apagamento: instituir uma ruptura entre os dois ethé por um apagamento de ethos mostrado; b) convergência: produzir uma convergência entre o ethos dito e o ethos mostrado, e c) desaparecimento: fazer desaparecer o ethos dito e aproveitar somente o ethos mostrado.

Neste texto, Maingueneau (2014) faz reflexões sobre alguns problemas ligados à interpretação do ethos, fazendo suposições sobre as possíveis maneiras que cada destinatário poderia incorporar aos ethé. Como seu texto é finalizado com a afirmação de que a Análise do Discurso está longe de ter explorado todo o potencial do conceito de ethos, nosso trabalho será aplicar essas dimensões e as possíveis estratégias que os destinatários podem adotar usando, para tanto, um corpus diferente daquele usado por Maingueneau: usaremos as entrevistas televisivas produzidas com as então presidentas sul-americanas.

\section{Interação face à face: análises dos ethé discursivos das presidentas sul- americanas}

Atores em interação: este é um fator que deve ser considerado quando pensamos no corpus de análise do nosso trabalho. A maneira como o ethos é construído na cena genérica conversacional na qual pessoas estão em interação pode modificar as maneiras e as estratégias de se engendrar os ethé discursivos. Como nos ensina Amossy (2010), na interação face à face é necessário que se façam ajustes da imagem de si em função das respostas do interlocutor; se ele reage favoravelmente ou não em relação à sua apresentação de si, por exemplo, e, então, você pode modificar e lhe propor outro ethos.

O essencial na interação face à face reside no fato de que a imagem projetada por cada um dos parceiros é objeto de uma reação imediata por parte do interlocutor. [...] $\mathrm{Na}$ interação propriamente dita, a confirmação ou a crítica do outro, ao contrário, é parte integrante do processo de produção, que muitas vezes se realiza por uma série de reajustes, de retomadas, ou de retificações. (AMOSSY, 2010, p. 132, tradução nossa).

Ao que concerne o gênero discursivo entrevista televisiva, pode-se dizer que ela tem como característica a conversação entre duas ou mais pessoas: o entrevistador faz perguntas para obter informações do entrevistado. Os jornalistas/apresentadores ocupam os papéis de entrevistadores e as posições de enunciador e coenunciador. As presidentas, por exemplo, ocupam o lugar de entrevistadas e também as posições de enunciadoras e coenunciadoras da cena enunciativa ${ }^{4}$. Outras características dessa cena

\footnotetext{
${ }^{3}$ No original em francês, estas estratégias são denominadas de: "l'effacement", "la convergence", e "la disparition".

${ }^{4}$ Utilizada na bibliografia pertinente como "encenação", "cenografia”, "contexto semiótico", "cena da enunciação", entre outros, a cena enunciativa é a própria situação de enunciação. Ela é responsável por definir as "[...] condições de enunciador e de co-enunciador, mas também o espaço (topografia) e o tempo (cronografia) a partir dos quais se desenvolve a enunciação." (MAINGUENEAU, 2001, p. 123). A cena enunciativa visa enfatizar a preeminência e a preexistência do lugar social em que os falantes se
} 
genérica é a gestão dos turnos de fala, o controle dos temas e dos tipos de perguntas. O entrevistado, geralmente, responde ao que lhe é perguntado pelo entrevistador, não podendo escolher o tema ou o direcionamento das indagações que lhe são feitas. Retomando os estudos feitos por Amossy (2010), no gênero entrevista ocorre uma dupla gestão da apresentação de si; mais do que isso, ocorre uma confrontação de imagens: de um lado, tem-se o entrevistado que quer se apresentar ao seu público; e, do outro, a imagem que é engendrada pelo seu entrevistador.

Dessa maneira, nos vídeos analisados, o quadro cênico é assim descrito: constrói-se uma cenografia de conversa, de diálogo amigável que coloca em contato indivíduos que mantêm uma interação entre si e o destinatário/telespectador que ouve/observa a interação dos atores. $\mathrm{O}$ gênero discursivo entrevista televisiva, apesar de ser suscetível às cenografias variadas, inúmeras vezes se atém a cenografias já validadas, como a conversa amigável.

Iremos analisar três entrevistas realizadas com as presidentas sul-americanas. Objetivando fazer um cotejamento entre as perguntas que são feitas às três presidentas, decidimos dividir essas análises em dois momentos: 1) entrevistas realizadas nos primeiros mandatos das presidentas; 2) comentários postados pelos internautas nos vídeos dessas entrevistas que estão disponíveis no YouTube.

Pensando-se na cena genérica da entrevista televisiva e no momento de sua enunciação, teríamos o seguinte plano enunciativo: estando o entrevistador e $\mathrm{o}$ entrevistado em interação, seus enunciados produziriam obrigatoriamente imagens de si e do outro. No enunciado do entrevistador encontraremos o ethos refletido, pois nele "refletem" a imagem que o jornalista possui de seu entrevistado. Esse ethos refletido pode ser, seguindo a distinção feita por Maingueneau, dito ou mostrado: "ethos dito" quando as características são explícitas no discurso; e "ethos mostrado" quando o que percebemos são vestígios deixados no enunciado. Já no enunciado do entrevistado, quando o enunciador construir, fixar seu próprio ethos, teremos o "ethos fixado" que também poderá ser dito ou mostrado.

Para que se pudesse fazer um cotejamento entre as imagens que são construídas nos enunciados dos jornalistas e nos enunciados das presidentas, verificando as semelhanças e as diferenças dessas construções, agrupamos os dados das três entrevistas feitas com as presidentas durante seus primeiros mandatos na seguinte tabela:

inscrevem e no qual cada falante alcança sua identidade. 
Tabela 1: Comparações das entrevistas televisivas feitas com as presidentas sul-americanas

\begin{tabular}{c|c|c|c}
\hline Presidenta & Michele Bachelet & Cristina Kirchner & Dilma Rousseff \\
\hline Data & $22 / 05 / 2009$ & $19 / 02 / 2010$ & $1 \% / 10 / 2010$ \\
\hline Veiculação da Entrevista $^{5}$ & Canal Encuentro & TV Pública Canalsiete & TV Record \\
\hline Tempo de entrevista & 50 minutos & 60 minutos & 15 minutos \\
\hline $\begin{array}{c}\text { Quantidade de indivíduos em } \\
\text { interação }\end{array}$ & 2 & 2 & 3 \\
\hline Quantidade total de questões & 9 & 15 & 6 \\
\hline Questões pessoais & 5 & 10 & 2 \\
\hline Questões de gênero & 0 & 3 & 8 \\
\hline Questões econômicas / históricas & 4 & 2 & 6 \\
\hline
\end{tabular}

Baseando-se nos postulados de Maingueneau (1997, 2001, 2008a, 2008b, 2010, 2013), a cena englobante do corpus aqui analisado indica um discurso político cujos parceiros se encontram no espaço-tempo de uma pós-eleição. Cada entrevista retrata mulheres que foram escolhidas pelo povo para, pela primeira vez, ocupar o cargo de Presidente da República de seus países. Tendo como característica a conversação entre duas ou mais pessoas, nas entrevistas o entrevistador faz perguntas para obter informações do entrevistado. Os jornalistas ocupam os papéis de entrevistadores e as posições de enunciador e coenunciador. As presidentas ocupam os lugares de entrevistadas e também as posições de enunciador e coenunciador da cena de enunciação. Assim, nos três vídeos analisados, o mesmo quadro cênico é constituído: constrói-se uma cenografia de conversa, de diálogo amigável que coloca em contato indivíduos que mantêm uma interação entre si e o coenunciador intérprete que ouve / observa a interação dos atores.

Partindo-se para as análises, temos a primeira presidenta eleita na América do Sul: Michelle Bachelet. Michelle foi entrevistada por Daniel Filmus em 22 de maio de 2009 e o fato curioso é que, das nove perguntas que lhe foram feitas, nenhuma era sobre gênero, ou seja, sobre "ser mulher". Isso nos chamou a atenção porque foi uma pergunta que aparecia constantemente em todas as entrevistas.

Para Bachelet, foram feitas cinco perguntas pessoais e quatro sobre história / economia. Ao relembrar a questão da ditadura, podemos observar a construção de um ethos refletido no enunciado do entrevistador Daniel Filmus. Vejamos a questão:

(01) Daniel Filmus - 25'36: Tem uma frase sua que se refere à Argentina, que é "não tenho nenhuma responsabilidade pelo o que se passou naquele momento, mas tenho responsabilidade para que não se repita". Me impactou muitíssimo essa frase. O que temos que fazer para que não se repita? (tradução nossa).

\footnotetext{
${ }^{5}$ As entrevistas estão disponíveis nos endereços eletrônicos:

Bachelet $-<$ https://www.youtube.com/watch? $=$ fWwMWS9FfPM\&t $=47 \mathrm{~s}>$;

Kirchner $-<$ http://www.youtube.com/watch?v=3YlihZ9aHeg $>$, e

Rousseff $-<$ http://www.youtube.com/watch?v=BkOQ5vUMPvY $>$.
} 
Pode-se dizer que, neste enunciado, transparece uma imagem da presidenta Bachelet que não foi produzida em seu próprio discurso, mas no discurso do entrevistador, mesmo sendo uma retomada das palavras da própria presidenta. É baseando-se em seu conhecimento do ethos pré-discursivo que o jornalista possuía da entrevistada que se pôde engendrar um ethos de credibilidade que se reporta ao ethos refletido de virtuoso. Mostrando-se conhecedor da trajetória da entrevistada, o enunciador entrevistador legitima o ethos de virtuoso da presidenta quando destaca que ela reconheceu erros anteriores e assumiu para si a responsabilidade para que esses erros não se repitam.

Em seguida, temos a resposta da presidenta Bachelet:

(02) Michelle Bachelet - 25'55: Já com o presidente [Ricardo] Lagos se trabalhou a concepção sobre uma política de direitos humanos que dizia "não há amanhã sem ontem", esse era um grande primeiro conceito. E "não há verdade se não há má notícia e reparação". E eu diria que esses conceitos têm guiado o que foi a política do governo passado e o meu. E o concreto é que o que tem significado por um lado é que é muito importante saber a verdade do ocorrido e outra eu digo em todos os meus discursos é que uma das verdades que se pode constatar na história Chilena de 1973 e no ano seguinte com brutal violação dos direitos humanos [...] e não somos capazes de resolver de maneira democrática essa diferença, há situações que temos que lamentar e que têm significado muita dor e muita tristeza para nosso povo. Cada vez que somos capazes de entender que a diversidade nos enriquece e que temos uma diferença grande, mas não nos vemos como uma nação de inimigos, mas uma nação de diferentes, de diversos, adversários frente a alguns temas, ou de interesses super legítimos contrapostos. Mas cada vez que somos capazes ou de concordar com o principal, ou buscar uma maneira racional para buscar resolver conflitos de interesses junto à sociedade, não vai voltar. (tradução nossa).

Neste enunciado, observa-se mais uma vez a construção do ethos fixado de seriedade da presidenta Michelle Bachelet. Desta vez, no entanto, um ethos mostrado. Ao comentar sobre o presidente que a antecedeu, sobre a necessidade de se falar a verdade, sobre a tristeza sofrida pelo povo, sobre a relevância de se buscar resolver os conflitos de interesse junto à sociedade para que a ditadura não volte mais a ser o regime de seu país, ela o faz de maneira séria, clara e objetiva. Mostra uma imagem de mandatária segura e capacitada para o cargo de presidente da república.

Cristina Kirchner foi entrevistada pelo mesmo jornalista - Daniel Filmus - em 19 de fevereiro de 2010. Para essa presidenta, foram feitas dez perguntas de ordem pessoal, duas sobre gênero e três sobre história e economia. Assim como foi perguntado para a presidenta Michelle Bachelet, também se perguntou para a presidenta Cristina Kirchner sobre quando ela havia pensado em ser presidente da Argentina.

Em uma das questões direcionadas a Cristina Kirchner, pode-se observar a existência de um ethos de identificação, mais especificamente, o ethos refletido de potência na questão formulada pelo enunciador entrevistador:

(03) Daniel Filmus - 44'37: E de onde vem toda a fonte de energia para, apesar de sozinha, consolidar as recentes conquistas profissionais? (tradução nossa).

Mesmo se referindo à competência da presidenta, revelando o ethos prédiscursivo que o enunciador entrevistador possui da entrevistada, neste enunciado é a questão da potência que prevalece. Segundo Charaudeau (2008), o ethos de potência é frequentemente relacionado ao sexo masculino porque nele são verificadas as proezas 
físicas pessoais por meio de comícios que exaltam a força, pela apresentação de si em voz altiva e palavras fortes. Nesta perspectiva, esse ethos é usado para transmitir a imagem de que não se é "[...] apenas um homem de palavra, mas também de ação" (CHARAUDEAU, 2008, p. 139). Desta maneira, ao retratar as ações bem sucedidas da presidenta Kirchner, o enunciador entrevistador deixa transparecer em seu enunciado esse ethos refletido de potência.

Em resposta à pergunta feita por Daniel Filmus sobre qual é a fonte de energia da presidenta para alcançar todas as suas conquistas, ela responde:

(04) Cristina Kirchner - 44'46: Perseverança, perseverança, perseverança. Sempre fui muito perseverante e muito responsável. E aceitar as coisas com dignidade sem se tornar vítima. Sem pensar que a culpa é toda do que passa, que sempre têm os demais, sempre temos nós mesmos. Então, não, eu sempre encontro força porque agora tenho a obrigação de ter força. Tenho a responsabilidade de ter forças. E se não tenho nenhuma, as invento. E se não as tenho, as retiro de algum lugar: das tripas, do estômago, da cabeça, de onde for. (tradução nossa).

Podemos dizer que, nessa interação pergunta/resposta, os ethé que foram engendrados tanto pelo entrevistador quanto pela entrevistada são convergentes, ou seja, no enunciado da presidenta Cristina Kirchner também transparece um ethos fixado de potência. Ao afirmar que a sua fonte de energia para alcançar suas conquistas profissionais era a sua perseverança, a presidenta se descreve como uma pessoa responsável e forte usando um tom de "mulher batalhadora" que não esmorece frente aos obstáculos.

Em sua primeira entrevista após ter sido eleita nas urnas brasileiras em $1^{\circ}$ de outubro de 2010, Dilma Rousseff é entrevistada por duas jornalistas mulheres: Ana Paula Padrão e Adriana Araújo. Para a presidenta brasileira foram feitas seis perguntas de cunho pessoal, duas sobre gênero e oito sobre história e economia. Uma das questões que analisamos aborda o tema do gênero:

(05) Ana Paula Padrão - 10’20: Presidente, é, a gente começou essa entrevista falando da questão de gênero. Não foi a tônica da sua campanha, mas ontem, no início do seu discurso a senhora tocou nesse assunto e disse uma frase emblemática: "Sim, a mulher pode". É uma frase muito forte.

Como nesse enunciado proferido pela jornalista Ana Paula Padrão ocorre um desaparecimento do ethos dito, ou seja, o ethos só pode ser construído por meios dos vestígios e das possibilidades de interpretação que a materialidade linguística permite, temos um exemplo de ethos refletido mostrado de virtuoso. Ao afirmar que a presidenta disse uma frase muito forte - "Sim, a mulher pode" - e que a questão do gênero não foi a tônica na campanha da presidenta, e pelo uso da adversativa "mas", pode-se compreender que a enunciadora jornalista considerou uma boa estratégia de campanha não se fazer apelo ao gênero feminino. Não apelar para uma questão polêmica fez com que se exaltasse a performance de um ethos virtuoso da presidenta.

Ao explicar por que a presidenta brasileira disse o enunciado emblemático, temos:

(06) Dilma Rousseff-10'38: Foi assim: eu estava no aeroporto. Me preparando para viajar. E, uma moça, uma menina de uns nove, dez anos, aproximou-se de mim e disse, o nome dela é Vitória e ela que quer te fazer uma pergunta. Virei pra menina, aliás pra mãe, até errei porque devia ter virado pra menina, e perguntei: que que você quer me perguntar, Vitória? Ela falou: Eu quero saber se a mulher pode? Aí eu respondi: Pode o quê? E ela me disse: Eu quero saber se 
mulher pode ser presidente da República. [interrupção jornalista: \{riso\} e a senhora respondeu]. E eu respondi: Sim, mulher pode. E aí, sabe o que que eu acho? Eu acho que a minha eleição torna sonhos que eu nunca tive, porque sempre me perguntam "você queria ser o quê?" e eu sempre disse "bailarina". Quando a gente, quando eu era criança, eu queria ser bailarina. Hoje, uma menina de nove, de cinco, de seis pode querer ser presidente da república porque agora tem uma mulher presidindo a República Federativa do Brasil.

A narrativa que explica o uso do enunciado "Sim, a mulher pode" que, inclusive, é muito parecido com o "Yes, we can" usado na campanha do ex-presidente Barack Obama, pode ser considerada bem conveniente para que vários ethé de identificação fossem engendrados. O nome da garotinha ser Vitória e a presidenta ter ganhado a eleição, ou seja, ter obtido a vitória é um fato bem curioso. Mas, para além das especulações, a materialidade linguística apresenta um ethos fixado dito de humanidade: ao assumir seu erro de falar com a mãe e não com a criança, a presidenta mostra explicitamente toda a sua humanidade e explica como deveria ter feito; posteriormente, quando retoma sua infância ao dizer que seu sonho era ser bailarina, ao demonstrar seus gostos e desejos, a enunciadora entrevistada mais uma vez assume seu ethos de humanidade. A imagem da bailarina, que é na sociedade em geral tão ligada à imagem da feminilidade, pode ter sido utilizada aqui para produzir efeitos de sentido para Dilma Rousseff que, muitas vezes, é retratada como uma "mulher durona" pela mídia. Observa-se, ainda, a presença do ethos fixado dito de seriedade quando a presidenta afirma que hoje as meninas podem querer ser presidente porque "[...] agora tem uma mulher presidindo a República Federativa do Brasil”.

\section{As novas práticas midiáticas e o processo de incorporação de ethé discursivos}

A popularização da internet produziu mudanças significativas e fundamentais para a sociedade como um todo. A partir da socialização das ferramentas de comunicação mediadas pelo computador, os indivíduos passaram a poder se construir, interagir e se comunicar (RECUERO, 2009). As alterações ocorridas nas atitudes e nas práticas desses sujeitos devem-se aos conteúdos transmitidos pelas atuais e diferentes mídias. Um exemplo de transformação das práticas midiáticas realizadas pelos usuários da internet é a possibilidade de compartilhar vídeos. O site de compartilhamento mais famoso YouTube - hospeda, desde 2005, uma enorme quantidade de filmes, documentários, videoclipes musicais, vídeos caseiros, entrevistas e transmissões ao vivo. Os vídeos ficam disponíveis para qualquer pessoa que queira assistir, além de ser possível adicionar comentários sobre eles.

Não há dúvidas de que a mídia mudou a maneira de se fazer política. Uma entrevista feita com uma presidenta sul-americana, por exemplo, fica disponível no YouTube e pode ser vista e comentada pelos internautas durante tempo indeterminado. Acredita-se que essas novas práticas dos indivíduos face aos conteúdos transmitidos pelas mídias também merecem outro tratamento analítico por parte dos pesquisadores. Partindo-se das problemáticas da recepção das mídias pelos indivíduos, da construção do sentidos feita por esses destinatários e utilizando-se como corpus os comentários postados nos vídeos das mesmas entrevistas televisivas feitas com as presidentas do Chile, da Argentina e do Brasil, neste momento pretendemos demonstrar gestos interpretativos que evidenciam como as imagens dessas presidentas podem ser construídas nos comentários postados pelos internautas. 
Para que essas análises fossem desenvolvidas, contou-se com algumas modificações para a noção de ethos e algumas reflexões sobre a complexidade das estratégias na gestão da relação entre ethos dito e ethos mostrado que os destinatários devem mobilizar para atribuir um ethos ao enunciador, estudos feitos por Maingueneau (2014) e já explicados anteriormente. Desta maneira, decidimos fazer algumas análises quantitativas dos comentários, buscando observar as práticas dos usuários perante os vídeos postados no YouTube e, por fim, aplicamos os novos conceitos / estratégias apresentadas por Maingueneau (2014) em um corpus diferente ao que ele utilizou em seu estudo inicial.

Foi a partir de 2005 que alguns jornais brasileiros passaram a ter suas versões online com recursos que permitiam aos leitores escrever seus comentários, porém, foi somente em 2008 que a publicação desses textos opinativos ganhou destaque. Entretanto, até 2010 era pequena a quantidade de pessoas que comentavam as notícias lidas. Hoje os comentários têm tanto destaque quanto as notícias ou os vídeos publicados (SILVA, 2016). Logo após os textos e vídeos, encontramos ícones com os enunciados imperativos: "comente", "opine", "faça seu comentário", "escreva seu comentário", "entre na conversa", "dê sua opinião". Essa nova prática constrói espaços de debates, lugares onde a polêmica pode se instaurar e isso modificou a relação dos indivíduos com os meios de comunicação. Eles passaram a ser lidos. Mas o que dizem os comentários? Eles sempre são sobre o tema abordado na reportagem? Nos vídeos com as presidentas, por exemplo, os internautas discutem sobre política? A busca dessas respostas justifica nossa empreitada em analisar os comentários postados nas entrevistas feitas com as presidentas sul-americanas ${ }^{6}$ e mostra que esses enunciados também constroem uma imagem dessas líderes políticas.

Ao observarmos o que enunciam esses comentários, foi possível separá-los em categorias para, em seguida, quantificá-los e compreender o que esses números poderiam significar.

\footnotetext{
${ }^{6}$ Cabe esclarecer que esses vídeos foram escolhidos como corpus de análise por terem tido uma grande quantidade de visualizações e de comentários quando comparados aos outros vídeos.
} 
Tabela 2: Categorias e porcentagens dos comentários

\begin{tabular}{|c|c|c|c|}
\hline & $\begin{array}{l}\text { Michelle } \\
\text { Bachelet }\end{array}$ & $\begin{array}{l}\text { Cristina } \\
\text { Kirchner }\end{array}$ & $\begin{array}{c}\text { Dilma } \\
\text { Rousseff }\end{array}$ \\
\hline Data da entrevista & $09 / 01 / 2010^{7}$ & $19 / 02 / 2010^{8}$ & $11 / 09 / 2011^{9}$ \\
\hline Número total de visualizações & 20.160 & 58.137 & 99.208 \\
\hline Número total de comentários & 68 & 157 & 163 \\
\hline Comentários positivos sobre a presidenta & $10 \%$ & $17 \%$ & $6 \%$ \\
\hline Comentários negativos sobre a presidenta & $38 \%$ & $6 \%$ & $15 \%$ \\
\hline Comentários positivos sobre o internauta & $4,5 \%$ & $4,5 \%$ & $4,5 \%$ \\
\hline Comentários negativos sobre o internauta & $22 \%$ & $37 \%$ & $24 \%$ \\
\hline Comentários positivos sobre história e economia & $1,5 \%$ & $2 \%$ & $4 \%$ \\
\hline Comentários negativos sobre história e economia & $6 \%$ & $11 \%$ & $12 \%$ \\
\hline Comentários de estranheza, ódio e intolerância & $3 \%$ & $11 \%$ & $3 \%$ \\
\hline $\begin{array}{l}\text { Comentários sobre o saber técnico do vídeo e do } \\
\text { jornalista }\end{array}$ & $3 \%$ & $5 \%$ & $18 \%$ \\
\hline Comentários que não possuem relação com o vídeo & $12 \%$ & $6,5 \%$ & $13 \%$ \\
\hline
\end{tabular}

Para as finalidades do nosso trabalho, iremos aplicar as noções teóricas de Maingueneau (2014) somente nos comentários positivos e negativos sobre as presidentas sul-americanas.

Ao dissertar sobre o apagamento do ethos mostrado, Maingueneau (2014) explica que o ethos discursivo não é levado em consideração, assim, o destinatário dá mais atenção ao ethos dito. De acordo com as análises de Maingueneau (2014), nesse tipo de enunciado as dimensões categóricas e ideológicas são privilegiadas. Fazendo um deslocamento metodológico e pensando em nossas análises, nesse ethos dito, que pode ser positivo ou negativo, encontram-se informações sobre o físico e a moral das presidentas.

Maingueneau (2014) comenta que, nessa estratégia de apagar o ethos mostrado, as informações são tão básicas que poderiam ser substituídas por uma não pessoa: "Mulher, 35 anos, morena". Em nosso corpus de análise podemos dizer que isso também ocorre, pois se não aparecessem os vocativos nos enunciados, ou se não colocássemos o nome das presidentas antes dos exemplos, não seria fácil identificar à qual presidenta 0 enunciado se referiria.

Exemplos positivo e negativo de Michelle Bachelet:

\footnotetext{
${ }^{7}$ Disponível em: $<$ https://www.youtube.com/watch?v=fWwMWS9FfPM $>$. Acesso em: 24 nov. 2016.

${ }^{8}$ Disponível em: $<$ https://www.youtube.com/watch?v=3YlihZ9aHeg $>$. Acesso em: 25 nov. 2016.

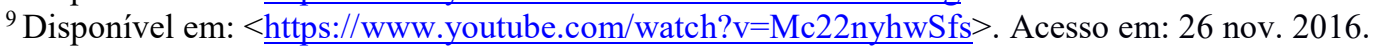


Internauta 1: Que mujer y presidenta hermosa.

(08) Internauta 2: de alguna manera uno propicia lo que hace, así que me parece que si la señora acepto el cargo de presidenta, fue porque quiso, esto es en lo único que diciento con ella, por todo lo demás, me parece una persona valiente, competente y muy válida.

(09) Internauta 3: vieja culia que no sabe dirigir el pais D:

(10) Internauta 4: Corrupta, mentirosa y sinverguenza!! Cero liderazgo, inepta e incapaz!! Definitivamente estabamos mucho mejor con la Dictadura!!

Exemplos positivo e negativo de Cristina Kirchner:

(11) Internauta 5: Una mujer con mucha personalidad y muy inteligente. No la olvidaremos.

(12) Internauta 6: Hermosa, Aguante cristina ii

(13) Internauta 7: Es una yegua ladroba

(14) Internauta 8: NORMA, LA MEJOR DE LA CORRUPTAS.

Exemplos positivo e negativo de Dilma Rousseff:

(14) Internauta 9: Dilma guerreira!

(15) Internauta 10: Dilma is great.

(16) Internauta 11: 3 PALAVRAS QUE COMBINAM COM VC E O SEU CARACTER Palhaça, Mentirosa e corrupta. apenas essas 3 palavras so 3 mais tem mais palavras

\section{Internauta 12: DILMA VOCÊ É UMA PUTA VELHA !}

Contrariamente ao que preconizou Maingueneau (2014), ao afirmar que nos enunciados que apresentam a estratégia do apagamento do ethos mostrado são privilegiadas as dimensões categóricas e ideológicas, isso não ocorreu em nosso corpus. Observamos a ocorrência de alguns ethé positivos pertencentes à dimensão experiencial, aquela que é estereotipada. Então, dizer que as presidentas são mulheres "com muita personalidade", "valentes" ou "guerreiras", estaríamos diante de palavras que abrangem essa dimensão. Acreditamos que isso se deve ao fato de o nosso corpus de análise ser diferente do que foi utilizado pelo referido autor. Em nosso caso, os predicados psicológicos foram exaltados, ethé positivos e negativos que faziam referência à credibilidade e à moral das presidentas: competente, corrupta, mentirosa, sem vergonha, sem liderança, inapta, incapaz, égua ladra, a melhor das corruptas, palhaça, mentirosa; e também ethé positivos e negativos que se referiam à aparência física dessas mulheres: bonita, ótima, puta velha, que mulher, presidente bonita, velha, ótima. Esses exemplos confirmam o total o uso exacerbado do ethos dito, tudo é explicitado, o destinatário não precisa buscar os vestígios nos enunciados, eles já estão lá, prontos para serem incorporados e, muitas vezes, em letras garrafais.

Ao que concerne à convergência entre ethos dito e ethos mostrado, Maingueneau (2014) nos ensina que o ethos mostrado poderia ser compreendido como sintomático da personalidade da locutora - fala como ela diz que é: clara e direta. Seriam exemplos os enunciados bem elaborados, equilibrados. Das dificuldades que essa estratégia poderia 
ter, o autor explica que o leitor deveria tomar uma decisão interpretativa ao incorporar o ethos mostrado como sintoma ou como estratégia. Como sintoma seria aceitar que a maneira de dizer é também a maneira de ser, seria a personalidade da pessoa. Não encontramos essa estratégia sendo utilizada nos comentários do vídeo da presidenta do Chile, mas podemos observar o enunciado postado no vídeo da presidenta Dilma:

(18) Internauta 13: Como eu queria que ela tivesse dado certo na Presidência. De verdade. Não torço contra o governo do meu país. Independente do partido. Participei ativamente da eleição dela em 2010, pelo ineditismo de termos uma mulher, outra visão, outro estilo. Ela foi vendida como a "supergerente" que entendia tudo, resolvia tudo, comandava tudo. E acabamos levando pra casa uma presidente que mal consegue completar uma única frase que faça sentido. Nessa entrevista, ainda em 2011, ela ainda parecia que seria uma ótima presidente. Que pena que não foi assim. Nos resta agora torcer pelo Temer e esperar as próximas eleições.

Ao fazer um deslocamento e usar essa estratégia para verificar como as imagens das presidentas são construídas nos comentários, ao dizer que ela "mal consegue completar uma única frase" (ethos dito), o internauta deixa implícito que a presidenta também não seria capaz de governar o país, pois, em sua opinião, não consegue fazer coisas mais simples. Assim, o destinatário poderá considerar que o ethos mostrado de incompetência é convergente ao ethos dito.

(19) Internauta 14: admiración absoluta por tener al fin un dirigente instruido, con una excelente oralidad y convicciones. Un aguante absoluto de mi parte!

Neste exemplo, retirado dos comentários do vídeo de Cristina Kirchner, também podemos verificar a convergência entre o ethos dito e o ethos mostrado. No ethos dito, o internauta menciona que a presidenta tem uma "excelente oralidade" e é instruída, e que por isso a admira. Esses atributos são convergentes ao ethos mostrado de competência que o internauta possui da presidenta.

Para dissertar sobre a estratégia de fazer desaparecer o ethos dito, Maingueneau (2014) nos traz um exemplo cuja descrição de si tem uma cenografia literária, a anunciante apresenta um poema que não fala diretamente dela mesma, mas transparece sua imagem por meio do ethos mostrado. Essa maneira de falar de si é contrária às expectativas do leitor comum e acaba definindo um destinatário ideal, uma vez que não seria qualquer pessoa capaz de compreender. Como não encontramos nenhuma ocorrência dessa estratégia, acreditamos que ela não seja considerada interessante pelos internautas, porque eles querem ser lidos e compreendidos, querem se expressar e por isso não abririam mão do ethos dito.

\section{Considerações finais}

Ethos refletido e ethos fixado, essas foram as principais noções que utilizamos em nossas análises interpretativas. Acreditamos que, com essa nomenclatura, fique mais simples compreender quando o ethos é construído no discurso do outro (refletido), e quando é constituído no discurso daquele fala de si (fixado). Em uma análise mais ampla, verificamos que, nos exemplos analisados da presidenta Michelle Bachelet, ocorreu a presença de ethos fixado de seriedade e de humanidade, enquanto o ethos refletido encontrado foi o de virtuoso. Já a presidenta Cristina Kirchner, em um de seus enunciados, produziu um ethos fixado de humanidade e em outro momento observamos a convergência da construção do ethos no enunciado do entrevistador e da presidenta: 
ambos engendraram ethos de potência. A presidenta brasileira, Dilma Rousseff, por outro lado, recebeu um ethos refletido negativo em sua interação com o enunciador entrevistador e, por isso, precisou usar a estratégia estudada por Amossy (2010) de reconstrução do ethos. Esse sujeito político, portanto, transformou seu ethos negativo em positivo: em seu enunciado, verificou-se o ethos fixado de inteligência. Outro ethos refletido construído no enunciado do enunciador jornalista para a presidenta Dilma foi o de virtuoso. Em sua resposta, a presidenta produziu ethos fixado de humanidade e de seriedade.

Sobre o fato de se analisar os comentários dos internautas postados nos vídeos das entrevistas das presidentas, temos algumas considerações: os sujeitos ordinários passaram a ter voz. Os sujeitos comuns passaram a ter suas vozes escutadas. Essas vozes se materializaram nas telas dos computadores. Essas palavras estão lá prontas para serem lidas, independentemente de quando elas foram postadas. Essa transformação nas práticas desses sujeitos tem grandes influências nas práticas da mídia e da política. Neste trabalho, percebemos que, na maioria das vezes, esses sujeitos postaram comentários cujos temas não eram necessariamente sobre as presidentas ou sobre a política, que eram os temas dos vídeos analisados, como os internautas brasileiros e argentinos que publicaram comentários sobre os próprios internautas. Mas, mesmo assim, é uma nova prática que pode delinear o perfil de cada povo e demonstrar sua relação com as novas mídias: por exemplo, os internautas chilenos que publicaram muitos comentários negativos sobre a presidenta Michelle Bachelet; ou os argentinos que expressaram ódio e intolerância em grande parte de seus comentários; ou ainda os internautas brasileiros que demonstraram seus conhecimentos técnicos sobre vídeo, som e jornalismo. Ainda sobre os comentários, fazemos uma ressalva: sabemos que eles passam por uma avaliação para, posteriormente serem postados na plataforma, ou seja, há uma mediação que poderia interferir no resultado das pesquisas, entretanto, neste artigo, consideramos somente os efeitos de sentido que a materialidade publicada produziu, mas poderiam ser outros, caso não houvesse esse filtro.

As análises mostraram que é preciso expandir os trabalhos que tratam o conceito de ethos e atestam que cada gênero discursivo apresenta suas especificidades e necessidades de se utilizar outras metodologias para analisar os mais variados tipos de corpora.

\section{REFERÊNCIAS}

AMOSSY, R. Dynamiques interactionelles: La gestion collective de l'ethos. In: Le présentation de soi: ethos et identité verbale. Paris : Presses Universitaires de France, 2010. p. 131-144.

L'ethos et ses doubles contemporains perspectives disciplinaires. Revue Langage \& Société - Ethos discursif, Paris: Éditions de la Maison des Sciences de l'Homme, n. 149, p. 13-30, 2014.

ARAÚJO, R. P. O panorama da Mulher na condição de esposa e mãe. Disponível em: $<$ http://www.klepsidra.net/klepsidra10/mulheres.html>. Acesso em: 12 abr. 2011.

BASSANEZI, C. Mulheres dos Anos Dourados. In: DEL PRIORE, M. (Org.). História das Mulheres no Brasil. 4. ed. São Paulo: Contexto, 2001. p. 607-639. 
CONFORTIN, H. Discurso e Gênero: a mulher em foco. In: GUILHARDI-LUCENA, M. I. (Org.). Representações do feminino. Campinas: Átomo, 2003. p. 107-123.

MAINGUENEAU, D. Novas tendências em análise do discurso. Campinas: Pontes, 1997. Fontes, 2001.

O contexto da obra literária: enunciação, escritor, sociedade. São Paulo: Martins . Gênese dos discursos. Curitiba: Criar Edições, 2005.

. Cenas da enunciação. São Paulo: Parábola Editorial, 2008a.

A propósito do Ethos. In: MOTTA, A. R.; SALGADO, L. (Org.). Ethos discursivo. São Paulo: Contexto, 2008b.

. Doze conceitos em análise do discurso. São Paulo: Parábola Editorial, 2010.

. Ethos, cenografia, incorporação. In: AMOSSY, R. Imagens de si no discurso: a construção do ethos. São Paulo: Contexto, 2013.

Retour critique sur l'ethos. Revue Langage \& Société - Ethos discursif. Paris: Éditions de la Maison des Sciences de l'Homme, n. 149, p. 31-48, 2014.

RECUERO, R. Redes sociais na internet. Porto Alegre: Sulina, 2009.

SANDRÉ, M. Ethos et interaction: analyse du débat politique Hollande-Sarkozy. Revue Langage \& Société - Ethos discursif. Paris: Éditions de la Maison des Sciences de l'Homme, n. 149, p. 69-84, 2014.

SILVA, J. C. V. da. Análise discursiva dos comentários: textualização e historicidade do/ sobre o Marco Civil da Internet. 2016. 111 f. Dissertação (Mestrado em Linguística) Centro de Educação e Ciências Humanas, Universidade Federal de São Carlos, São Carlos, 2016.

Recebido em: 11/09/2017

Aprovado em: 09/04/2018 